\title{
Efecto in vitro del Extracto Proteico de Macroquistes de Sarcocytis aucheniae sobre la Viabilidad y Degranulación de Leucocitos de Conejo (Oryctologus cuniculus)
}

\author{
In vitro Effect of the Protein Extract of Sarcocystis aucheniae Macrocysts on \\ THE Viability and Degranulation of RabBit (Oryctologus cuniculus) Leukocytes
}

\author{
María del Carmen Inga ${ }^{1}$, Alberto Manchego S. ${ }^{1,3}$, Nieves Sandoval C. ${ }^{2}$, \\ Cesar Burga C, ${ }^{1}$, Gina Castro S. ${ }^{1}$, Hermelinda Rivera G. ${ }^{1}$
}

\section{Resumen}

En el presente trabajo se buscó determinar el efecto tóxico in vitro del extracto proteico de macroquistes de Sarcocystis aucheniae sobre leucocitos circulantes de conejo (citotoxicidad). Se trabajó con cinco concentraciones de extracto proteico $(0.5,1,50$, $500,1000 \mathrm{ng} / 100 \mu \mathrm{l}$ ) en una población de 500000 leucocitos/ml incubados por 1 y 12 horas en un medio de cultivo a $37^{\circ} \mathrm{C}$. Se determinó la viabilidad celular por exclusión con azul de tripán y la degranulación de enzimas leucocitarias (mieloperoxidasa y glucosaminidasa) mediante electroforesis en geles de poliacrilamida y transferencia a membranas de nitrocelulosa (Western blotting). El recuento de células a $1 \mathrm{~h}$ de incubación demostró una alta mortalidad (57.7 a 58.1\%), siendo a las 12 h entre 65.2 y $99.4 \%$, y sin diferencia estadística entre las medias del número de leucocitos que sobreviven a cada tratamiento. La mortalidad en el grupo control de suero fisiológico alcanzó 5 y $57 \%$ a 1 y 12 h de incubación, respectivamente. En la degranulación de leucocitos se observó la secreción de proteínas diferentes a aquellas en el grupo control inoculado con suero fisiológico, evidenciado por la tinción de bandas en las membranas de transferencia. Se concluye que el extracto proteico de macroquistes de $S$. aucheniae es altamente citotóxico para los leucocitos de conejo y se observa la secreción de proteínas.

Palabras clave: Sarcocystis aucheniae, mieloperoxidasa, glucosaminidasa, leucocito, conejo

\section{Abstract}

The aim of this study was to determine the in vitro toxic effect of the protein extract of macrocysts of Sarcocystis aucheniae on circulating rabbit leukocytes (cytotoxicity).

\footnotetext{
${ }^{1}$ Laboratorio de Microbiología y Parasitología Veterinaria, ${ }^{2}$ Laboratorio de Histología, Embriología y Patología Veterinaria, Facultad de Medicina Veterinaria, Universidad Nacional Mayor de San Marcos, Lima, Perú

${ }^{3}$ E-mail: amanchegos@gmail.com
}

Recibido: 30 de junio de 2015

Aceptado para publicación: 4 de marzo de 2016 
Five concentrations of the protein extract $(0.5,1,50,500,1000 \mathrm{ng} / 100 \mu \mathrm{l})$ were exposed to a population of 500000 leukocystes/ml for 1 and $12 \mathrm{~h}$ in a culture medium at $37^{\circ} \mathrm{C}$. The cell viability was evaluated by trypan blue exclusion and the enzyme degranulation of leukocytes (myeloperoxidase and glucosaminidase ) by polyacrylamide gel electrophoresis and transfered to nitrocellulose membranes (Western blotting). The cell count at $1 \mathrm{~h}$ of incubation showed high mortality ( 57.7 to $58.1 \%$ ), whereas at $12 \mathrm{~h}$ varied from 65.2 to $99.4 \%$, and without statistical differences between the mean of leukocytes that survive in each treatment. Mortality in the control group (saline) was 5 and $57 \%$ at 1 and $12 \mathrm{~h}$ of incubation respectively. On leukocyte degranulation the inoculated groups secreted different proteins than the control group inoculated with saline as evidenced by staining bands in controlling protein transfer membranes. It was concluded that the protein extract of $S$. aucheniae macrocysts is highly cytotoxic to rabbit leukocytes and protein secretion is observed.

Key words: Sarcocystis aucheniae, myeloperoxidase, glucosaminidase, leukocyte, rabbit

\section{INTRODUCCIÓN}

Sarcocystis aucheniae causa infecciones importantes en alpacas y llamas (Guerrero et al., 1967) derivando en severos problemas sanitarios en la producción alpaquera del Perú y el mundo. Desde el punto de vista veterinario, los estadios de desarrollo del parásito de importancia se encuentran en los hospedadores intermediarios (Urquhart et al., 1996); sin embargo, desde el punto de vista de salud pública, el hombre puede actuar, no solo como hospedador definitivo de $S$. bovihominis y S. suihominis, sino que, además, se considera como causal de zoonosis tóxica, ya que se han reportado evidencias de trastornos gastroentéricos en personas que consumieron carne insuficientemente cocida infectada con $S$. aucheniae (Leguía y Clavo, 1989) y $S$. bovihominis (Hiepe et al., 1979). Además, estos cuadros son ampliamente conocidos por los campesinos de las zonas altoandinas y son atribuidos a la «frescura de la carne» (Leguía, 1991).

Los macroquistes de Sarcocystis aucheniae producen diversos cuadros de intoxicación alimentaria en humanos. Asimismo, los conejos son altamente susceptibles cuando son inyectados intramuscularmente con extractos proteicos, pero es menos severo en ratones (Sam et al., 1998; Chileno et al., 2011). Los quistes de Sarcocystis contienen una sustancia proteica denominada sarcocistina que posee actividad neurotóxica (Hiepe et al., 1981). La sarcocistina es considerada como una endotoxina que actúa a nivel del músculo cardiaco y tejido nervioso gastrointestinal (Hiepe et al., 1981).

La variada susceptibilidad del curso de la intoxicación en diversas especies y las lesiones que se observan en ellas indican la acción neurotóxica de las toxinas, pero también la posible participación de células leucocitarias productoras de citoquinas proinflamatorias y contenidos lisosomales (degranulación). Por este motivo, debe establecerse el grado de participación del sistema inmune, ya que la fisiopatología de estas intoxicaciones aún es desconocida. La evidente susceptibilidad de los conejos permite emplearlos como un modelo animal para investigar la fisiopatología de las intoxicaciones por proteínas de S. aucheniae. La identificación de los factores que intervienen en la fisiopatología de las intoxicaciones permitirá adecuar medidas terapéuticas para el tratamiento y control de las mismas.

Se hipotetiza que la exposición de los leucocitos de conejo a las proteínas contenidas en el extracto de macroquistes de $S$. aucheniae provoca citotoxicidad y degranulación. El presente trabajo tuvo como 
objetivos cuantificar el nivel citotóxico del extracto de macroquistes de $S$. aucheniae en leucocitos de conejo e identificar la presencia de sustancias de degranulación provenientes de los leucocitos afectados.

\section{Materiales y Métodos}

\section{Lugar de Estudio y Muestras}

El estudio se realizó en el Laboratorio de Microbiología y Parasitología Veterinaria, sección Virología, de la Facultad de Medicina Veterinaria (FMV) de la Universidad Nacional Mayor de San Marcos (UNMSM), Lima, Perú. Los macroquistes de Sarcocystis aucheniae fueron colectados en el laboratorio a partir de trozos de carne obtenidas del cuello de cinco alpacas adultas (5-7 años de edad) infectadas naturalmente y sacrificadas en el camal municipal de la provincia de Huancavelica (Huancavelica, Perú). Las muestras de sangre en frascos con heparina se obtuvieron de tres conejos Nueva Zelanda, de 2 a $3 \mathrm{~kg}$ de peso y de 1 año de edad, procedentes del bioterio de la FMV.

\section{Extracto Proteico de Macroquistes de S. aucheniae}

Para obtener el extracto proteico total de macroquistes de $S$. aucheniae, se tomaron $10 \mathrm{~g}$ del total de macroquistes colectados, conservando sus envolturas quísticas, y fueron colocados en tampón fosfato salino (PBS) evitando su deshidratación. Los macroquistes fueron molidos en un mortero frío con $5 \mathrm{ml}$ de PBS hasta obtener una pasta homogénea, la que fue centrifugada a 5000 $g$ por $10 \mathrm{~min}$ a $4{ }^{\circ} \mathrm{C}$. Se eliminó el sobrenadante y el pellet fue resuspendido en Medio Mínimo Esencial (MEM) en la proporción 1:2. Seguidamente, el pellet de los macroquistes (conformado generalmente por cistozoitos) con $10 \mathrm{ml}$ de MEM fue sometido a ultrasonicación (Fisher-300) durante 60 ciclos/s en intervalos de $60 \mathrm{~s}$. Se observó la destrucción de las membranas celulares por microscopía. Los productos sonicados fue- ron centrifugados a $3000 \mathrm{~g}$ durante $20 \mathrm{~min}$ según el protocolo descrito por Sam et al. (1998). El sobrenadante y el pellet fueron colectados independientemente y almacenados a $-20^{\circ} \mathrm{C}$.

La concentración de proteínas totales (antígenos totales) del extracto obtenido del pellet fue medido con el Qubit ${ }^{\circledR} 3.0$ Quantitation Starter Kit (Invitrogen, EEUU), siguiendo las instrucciones del fabricante. $\mathrm{La}$ concentración de antígeno total fue ajustada mediante dilución en MEM libre de antibióticos a fin de obtener diluciones de 0.5 , 1, 50, 500, $1000 \mathrm{ng} / 100 \mu \mathrm{l}$ (medidas por espectrofotómetro a una longitud de onda de $540 \mathrm{~nm})$.

\section{Cultivo de Leucocitos de Conejo}

La sangre fue centrifugada a $2000 \mathrm{~g}$ por 5 min. Los leucocitos fueron recuperados (capa flogística) en crioviales de $2 \mathrm{ml}$ e incubados con tampón de lisis de eritrocitos por 15 min, centrifugados y lavados 3 veces con PBS (0.15M pH 7.2). Los leucocitos obtenidos se tiñeron con azul de tripán al $0.3 \%$ en proporción 1:2 con los leucocitos resuspendidos en MEM. Se contaron las células vivas empleando una cámara de Neubauer en microscopio óptico 400x. La concentración de leucocitos se ajustó a 500000 células/ml.

Paralelamente, se desarrolló un ensayo empleando sangre humana a fin de constatar la presencia de las proteínas de degranulación leucocitaria. Se utilizaron cuatro alícuotas: el plasma, que posteriormente se usó en su estado puro sin dilución; una tratada de la misma manera que la de sangre de conejo (usando el buffer de lisis) en la obtención de leucocitos, y las otras dos conteniendo la capa flogística y el cúmulo eritrocitario, las cuales fueron diluidas, una en agua bidestilada y la otra en PBS, llevadas a congelación por 10 min y posteriormente descongeladas. Estas muestras no fueron enfrentadas con el extracto de macroquistes, sino que se emplearon para evaluar el efecto de la degranulación leucocitaria. 


\section{Efecto sobre la Viabilidad}

El extracto proteico de macroquistes de S. aucheniae en las diferentes diluciones $(0.5$, $1,50,500$ y $1000 \mathrm{ng} / 100 \mu \mathrm{l}$ ) se enfrentó a los leucocitos de conejo (500 000 células/ml) en placas de cultivo de 24 pocillos a $37^{\circ} \mathrm{C}$ por 1 y $12 \mathrm{~h}$. Como grupo control se empleó una suspensión de leucocitos tratada con PBS. Posterior a la incubación, las células fueron resuspendidas en su medio por raspado y centrifugadas a $2000 \mathrm{~g}$ por $5 \mathrm{~min}$, y el pellet resuspendido en PBS. Luego, se procedió al conteo con cámara de Neubauer previa tinción con azul de tripán.

\section{Efecto sobre la Degranulación de Leucocitos}

\section{Precipitación de proteínas}

Se tomó $100 \mu 1$ del sobrenadante de cada tratamiento $(1 \mathrm{y} 12 \mathrm{~h}$ ), se agregó $25 \mu \mathrm{lde}$ ácido tricloroacético (TCA), se refrigeró a $4{ }^{\circ} \mathrm{C}$ por 10 min y se congeló a $-20^{\circ} \mathrm{C}$ por $24 \mathrm{~h}$. El sobrenadante precipitado con TCA se centrifugó a $12000 \mathrm{rpm}$ por $5 \mathrm{~min}$ a $4{ }^{\circ} \mathrm{C}$ y se eliminó el sobrenadante. Se adicionó $100 \mu 1$ de acetona, se centrifugó a $12000 \mathrm{rpm}$ por 5 min a $4{ }^{\circ} \mathrm{C}$, se eliminó el sobrenadante, se reconstituyó con $40 \mu 1$ de PBS y se almacenó a $-20{ }^{\circ} \mathrm{C}$.

\section{Electroforesis de muestras de proteínas}

Se empleó la técnica de electroforesis en gel de poliacrilamida con dodecilsulfato sódico (SDS PAGE) para la visualización de las proteínas contenidas en el sobrenadante de los tratamientos, empleando un tanque de electroforesis vertical (Biorad, EEUU). Se realizó la electroforesis aplicando corriente continua (50 v durante $20 \mathrm{~min}$ y luego $75 \mathrm{v}$ durante $3 \mathrm{~h}$ ) a las muestras en minigeles de $8 \times 10 \mathrm{~cm}$ y $0.75 \mathrm{~mm}$, incluido el marcador de peso molecular pre-teñido de Perfect Protein $^{\text {TM }}$ Markers 10-225 kDa.
Transferencia de las proteínas a la membrana

Una vez realizada la separación electroforética de las proteínas por su peso molecular, se les transfirió desde el gel de electroforesis a la membrana de nitrocelulosa, aplicando corriente continua de $80 \mathrm{v}$ por 150 min. La migración ocurre del cátodo (-) hacia el ánodo (+).

\section{Bloqueo de los sitios de unión ines- pecíficos}

La membrana de nitrocelulosa obtenida después de la transferencia de proteínas, fue colocada en $5 \mathrm{ml}$ de buffer de bloqueo e incubada por $1 \mathrm{~h}$ a temperatura ambiente en agitación constante.

Adición de anticuerpos primarios y secundarios

Los anticuerpos (Ac) primarios usados fueron IgG de cabra policlonal «HEXA N19» (sc 48530) (Santa Cruz Biotechnology, EEUU) para detectar glucosaminidasa, IgG de conejo policlonal «MPO heavy chain $(\mathrm{H}-$ 300)» (sc 33596) (Santa Cruz Biotechnology, EEUU) para detectar mieloperoxidasa. Los anticuerpos secundarios utilizados fueron el IgG de conejo anticabra e IgG policlonal de cabra anticonejo conjugados con HRPO (peroxidasa), ambos del laboratorio antes mencionado.

En esta etapa se eliminó el buffer de bloqueo y se reemplazó con la solución de Ac primarios diluidos a la razón de 1/1000 en el buffer de bloqueo. Se dejó incubar por $1 \mathrm{~h}$ a temperatura ambiente con agitación constante.

Al emplear bandejas de plástico, el volumen de Ac primario y secundario se incrementa a $50 \mathrm{ml}$. Luego, se removió la membrana y se lavó 4 veces mediante agitación con 200 ml de solución salina tamponada 
Cuadro 1. Resultados del enfrentamiento de los leucocitos de conejo con el extracto de macroquistes de Sarcocystis aucheniae a 1 y 12 horas de incubación

\begin{tabular}{|c|c|c|c|c|c|c|}
\hline & $\begin{array}{c}1000 \mathrm{ng} / \\
100 \mu \mathrm{l}\end{array}$ & $\begin{array}{c}500 \mathrm{ng} / \\
100 \mu \mathrm{l}\end{array}$ & $\begin{array}{l}50 \mathrm{ng} / \\
100 \mu \mathrm{l}\end{array}$ & $\begin{array}{l}1 \mathrm{ng} / \\
100 \mu \mathrm{l}\end{array}$ & $\begin{array}{c}0.5 \mathrm{ng} / \\
100 \mu \mathrm{l}\end{array}$ & $\begin{array}{c}\mathrm{SF} / 100 \\
\mu \mathrm{l}\end{array}$ \\
\hline \multicolumn{7}{|l|}{1 hora de incubación } \\
\hline $\operatorname{Vivos}\left(\times 10^{4} \mathrm{cel} / \mu \mathrm{l}\right)$ & 211.5 & & 209.5 & & 210.5 & 475.0 \\
\hline Mortalidad (\%) & 57.7 & & 58.1 & & 57.9 & 5.0 \\
\hline \multicolumn{7}{|l|}{12 horas de incubación } \\
\hline $\operatorname{Vivos}\left(\times 10^{4} \mathrm{cel} / \mu \mathrm{l}\right)$ & 16 & 3 & 40 & 45 & 174 & 214 \\
\hline Mortalidad (\%) & 96.8 & 99.4 & 97.0 & 71.0 & 65.2 & 57.0 \\
\hline
\end{tabular}

con Tris y Tween 20 (TTBS), de 10 a 15 min por lavado. Seguidamente, se embebió en el Ac secundario conjugado en diluido en buffer de bloqueo. Los Ac secundarios comerciales se diluyeron a $1 / 200$ e igualmente se incubaron por $1 \mathrm{~h}$ y, en forma similar al procedimiento anterior, se removió la membrana y se lavó 4 veces mediante agitación con 200 $\mathrm{ml}$ de TTBS, de 10 a 15 min por lavado.

\section{Revelado}

Se empleó la técnica de visualización de membrana mediante substratos cromogénicos amino-9-etil-carbazol (AEC) (Sigma-Aldrich, EEUU). En esta fase se emplea la membrana de nitrocelulosa después del proceso de transferencia y se revelan las proteínas transferidas y sondeadas con complejo anticuerpo primario unido al anticuerpo-enzima secundario con una solución salina tamponada con Tris (TBS) y el reactivo AEC.

Se empleó amino-etil-carbazol $(2.0 \mathrm{mg})$ en dimetilformamida $(0.5 \mathrm{ml})$. Una vez diluido, se añadió amortiguador acetato $50 \mathrm{mM}$ pH 5.0 (9.5 ml) $10 \mathrm{~min}$ antes del revelado e inmediatamente antes de usar $10 \mu \mathrm{lde}$ peróxido de hidrogeno al $3 \%$. Se agregó la solución de revelado en una bandeja conteniendo la membrana de nitrocelulosa procesada con los anticuerpos por un aproximado de 3 a 5 min hasta que se observaron las bandas tenidas de marrón y luego fueron lavadas con agua destilada.

\section{Análisis Estadístico}

Se utilizó la prueba de análisis de varianza en los resultados de los grupos tratados, utilizando los valores de las medias del recuento de células vivas por tratamiento.

\section{Resultados}

\section{Viabilidad Leucocitaria}

Se observó el 57.7 al 58.1\% de mortalidad leucocitaria en los grupos tratados y con 1 h de incubación, y sin diferencia estadística entre tratamientos. La mortalidad en el grupo control (suero fisiológico) alcanzó el 5\% a 1 h de incubación (Figura 1, Cuadro 1). 


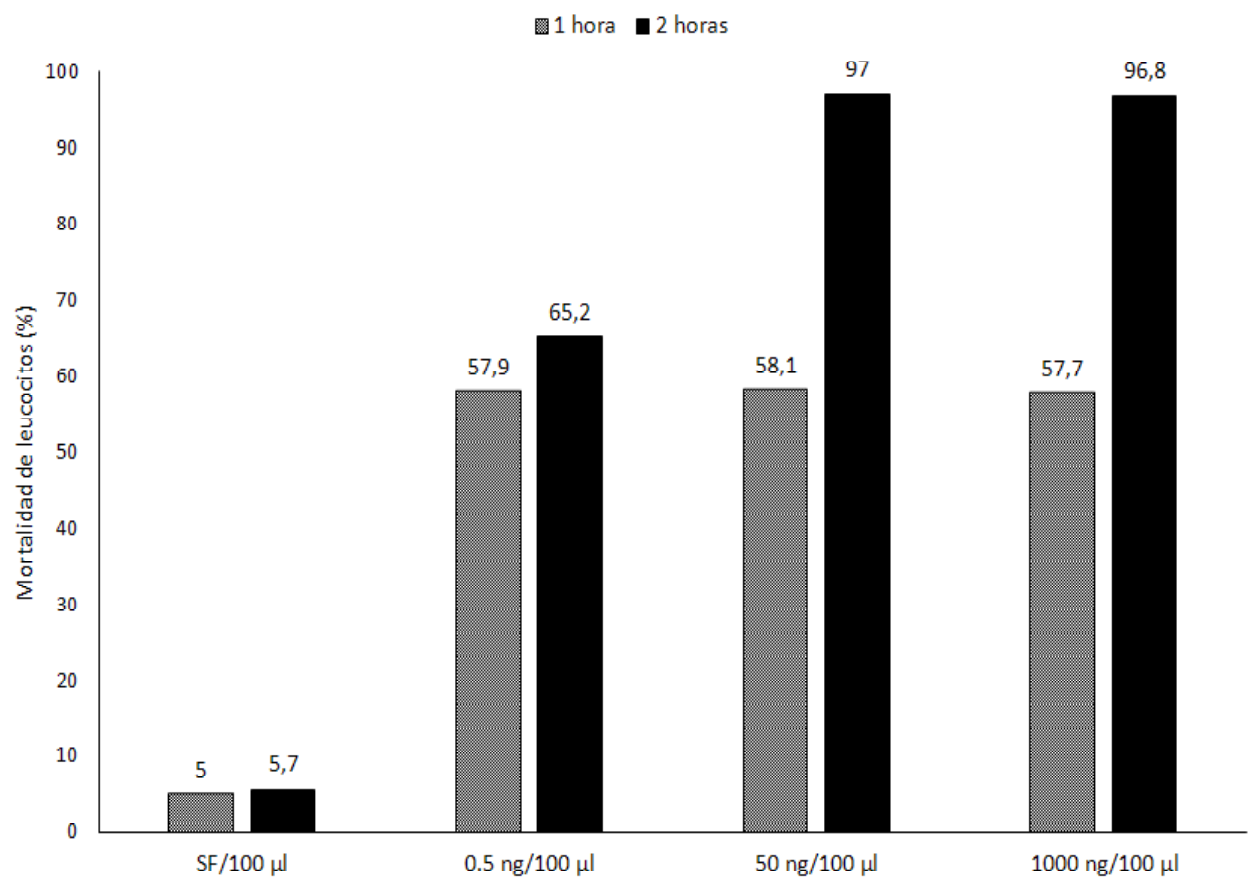

Figura 1. Mortalidad leucocitaria (de conejo) a 1 y 12 horas de incubación con extracto proteico de Sarcocystis aucheniae

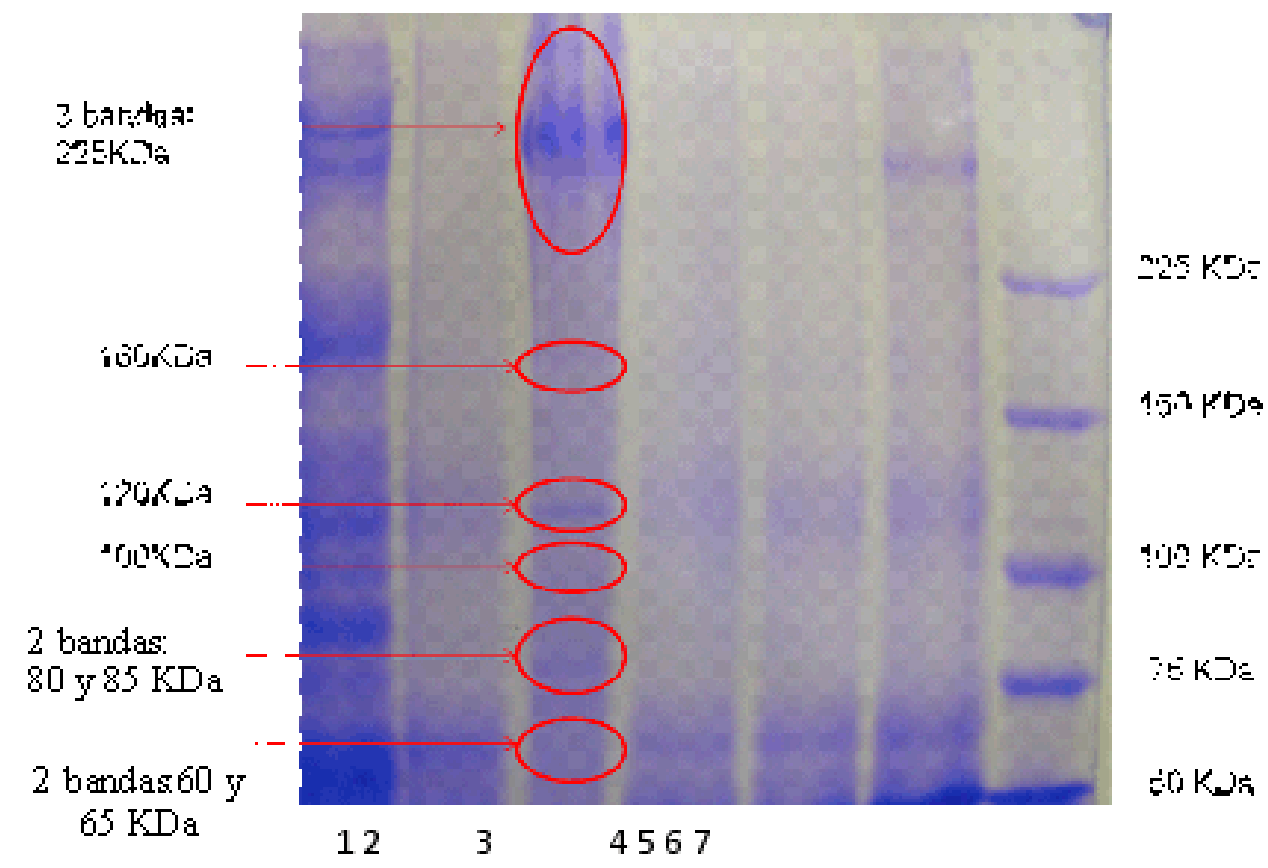

Figura 2. SDS-PAGE teñido con azul de Coomasie del sobrenadante de los tratamientos de leucocitos de conejo con extractos de macroquistes de Sarcocystis aucheniae. 1. Plasma de conejo; 2. Plasma de conejo diluido 1:50; 3. Extracto proteico de $S$. aucheniae; 4, 5 y 6 . Tratamiento de leucocitos con $0.5,50$ y $1000 \mathrm{ng} / 100 \mu 1 \mathrm{de} S$. aucheniae, respectivamente; 7. Marcador Novagen Perfect Protein ${ }^{\mathrm{TM}}$ Markers, 10$225 \mathrm{kDa}$ 


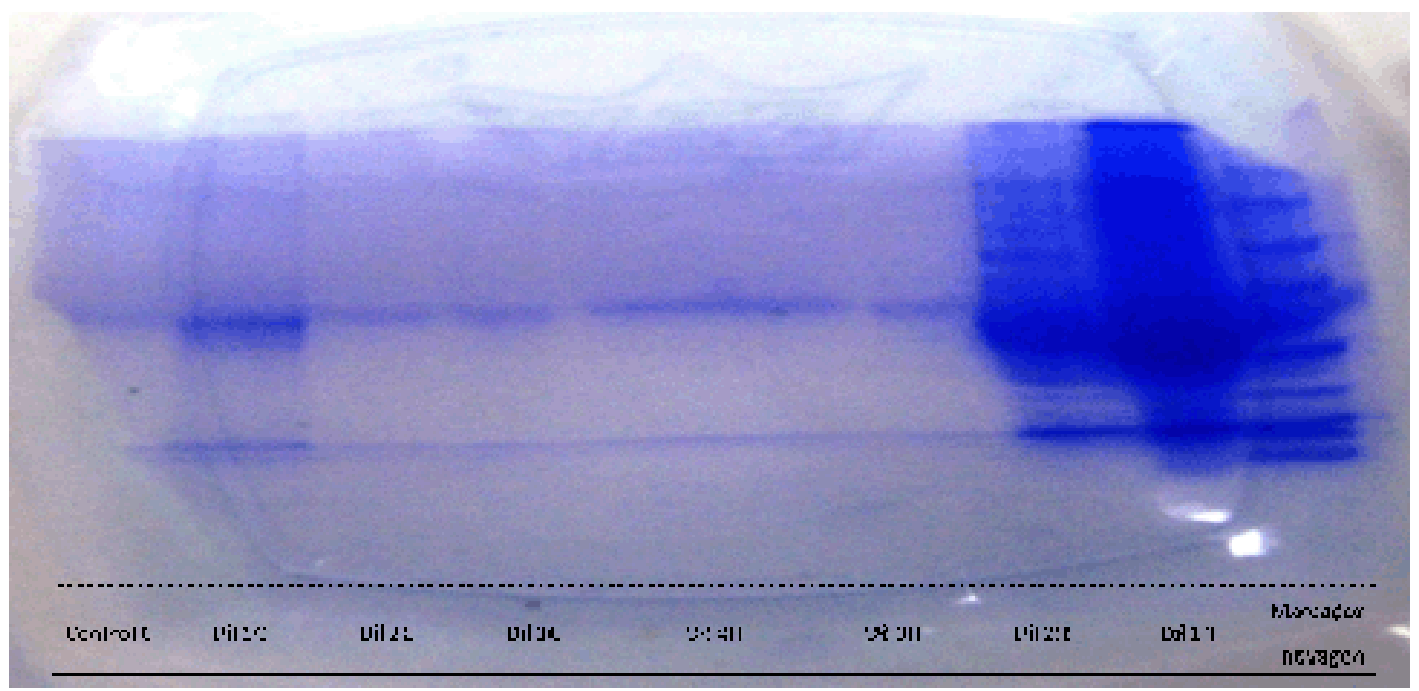

Figura 3. Gel de electroforesis teñido con azul de Coomassie. Se observan las bandas de proteínas de diversos tamaños en leucocitos de conejo tratados con extracto de Sarcocystis auchenia

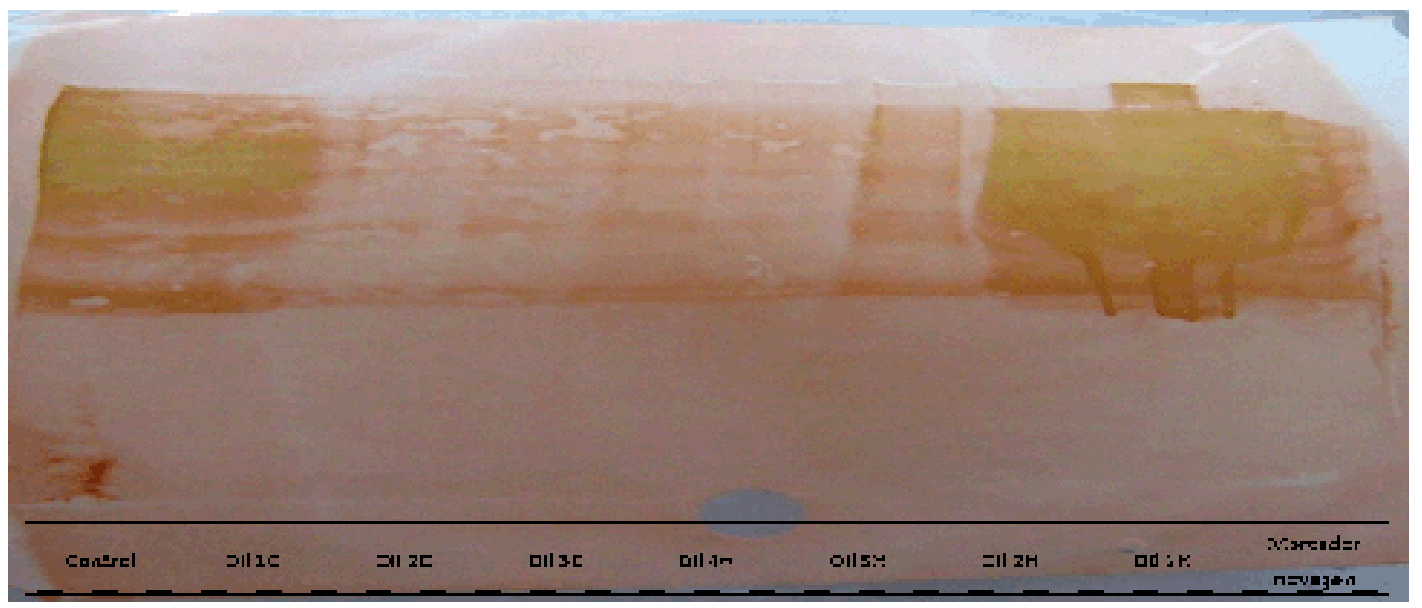

Figura 4. Western blotting de las proteínas de los geles de electroforesis utilizando anticuerpos contra mieloperoxidasa y glucosaminidasa. Observe las bandas marrones que identifican a las proteínas que se incrementan dependiendo de la concentración del extracto de macroquistes de $S$. aucheniae 


\section{Degranulación de Leucocitos}

La degranulación de leucocitos de conejo en presencia de extracto proteico de $S$. aucheniae, empleando la técnica SDS PAGE, mostró una secreción de proteínas distintas a las observadas en el control inoculado con suero fisiológico en algunos tratamientos. Se observó proteínas celulares de $160,120 \mathrm{kDA}$ y otras por debajo de los 75 $\mathrm{kDa}$ que se incrementan con el aumento de la concentración del extracto de macroquistes. Es importante mencionar que la MPO monomérica pesa $72 \mathrm{kDa}$, mientras que HEXA madura pesa $54 \mathrm{kDa}$ (Tizard, 2009).

Asimismo, se logró observar otras 10 proteínas: 3 por encima de los $225 \mathrm{kDa}$, una alrededor de $160 \mathrm{kDa}$, una de $120 \mathrm{kDa}$, una de $100 \mathrm{kDa}$, dos entre 80 y $85 \mathrm{kDa}$ y otras dos alrededor de 60 y 65 kDa (Figuras 2-4). Por otro lado, se encontró un incremento de la concentración entre las proteínas identificadas asociado al incremento de la concentración del extrato de macroquistes. Se observa que las de mayor concentración pesan más de $225 \mathrm{kDa}$, la banda de $120 \mathrm{kDa}$, y las bandas de 80-85 kDa que son proteínas del S. aucheniae.

\section{Discusión}

En el presente trabajo se establece la viabilidad leucocitaria in vitro de los leucocitos de conejo expuestos a un extracto total de macroquistes de $S$. aucheniae, observándose una viabilidad con concentraciones iguales o menores a $0.5 \mathrm{ng} / 100 \mu \mathrm{l}$ de extracto, pero tóxico a $50 \mathrm{ng} / 100 \mu \mathrm{l}$. Un compuesto se considera citotóxico cuando la viabilidad es inferior al $80 \%$ y con un coeficiente de variación no mayor al 20\% (Rodríguez et al., 2004). Los lisados de macroquistes de $S$. aucheniae contienen compuestos proteicos de acción tóxica compatibles con los constituyentes de la toxina sarcocistina (Senaud y Cerna, 1978; Hiepe et al., 1981). La toxina ocasiona la muerte en conejos debido a alte- raciones agudas en órganos vitales, especialmente en órganos detoxificadores como el riñón e hígado. Asimismo, se ha demostrado la resistencia de ratones y cobayos a la acción tóxica de lisados de estos macroquistes (Sam et al., 1998).

La respuesta inmune en el hospedero intermediario que se desarrolla frente a los protozoos es similar a la que se desencadena en bacterias, donde en este caso, los antígenos protectores de $S$. aucheniae están asociados a la formación de fases sexuales. La expresión de la inmunidad depende de la actividad de las células T que colaboran con la producción de anticuerpos neutralizantes contra los esporozoitos, así como también la liberación de linfocinas para inhibir la multiplicación de las fases intracelulares, tratando de conseguir la disminución de los síntomas clínicos y la reducción del número de ooquistes (Urquhart et al., 2001). Hinostroza et al. (2015) demostraron que el extracto de macroquistes de $S$. aucheniae a dosis de 0.5, 1, 50, 500, 1000 $\mathrm{ng} / \mathrm{ml}$ a 1,12 y $24 \mathrm{~h}$ de incubación in vitro con leucocitos circulantes de alpaca indujo una respuesta inflamatoria evidenciada por la detección y cuantificación relativa de las citoquinas proinflamatorias IL- $1 \alpha$, IL- $1 \beta$, IL6 y TNF- $\alpha$.

A diferencia de los macrófagos, los granulocitos polimorfonucleares son células fagocíticas de vida corta, que por acción de factores quimiotácticos de tipo humoral atraviesan el endotelio vascular por medio de procesos de marginación (adherencia de células endoteliales) y diapédesis, penetrando finalmente en el intersticio tisular. Los granulocitos constituyen una de las primeras líneas de defensa frente a microorganismos invasores. Poseen un núcleo lobulado y se subdividen en neutrófilos, eosinófilos y basófilos, según la avidez de sus gránulos citoplasmáticos por tinciones neutras, ácidas o básicas, respectivamente. Parte de los efectos inflamatorios provocados por la presencia de los leucocitos polimorfonucleares (PMNs) en los tejidos son atribuidos a la liberación del contenido de sus 
gránulos en el fagolisosoma o en el medio extracelular. Los neutrófilos emplean péptidos antimicrobianos y proteínas, los cuales destruyen microorganismos invasores (Tizard, 2009).

En el presente trabajo los leucocitos circulantes de conejo expresaron proteínas de degranulación cuando fueron estimulados con el extracto completo de $S$. aucheniae a 1 y 12 horas de exposición in vitro. Esto indica que los leucocitos son estimulados por moléculas que inducen las transducciones de señales que desencadenan la degranulación (Lacy, 2006). El componente leucoitario de la sangre del conejo está constituida principalmente por linfocitos (50-63\%), neutrófilos (39-43\%) y eosinófilos (0-5\%), permitiendo que muchos de ellos reconozcan las moléculas que estimulen su degranulación (Giusti et al., 2012).

En el presente trabajo se demuestra la liberación de mieloperoxidasa por los leucocitos sanguíneos del conejo frente al extracto de macroquistes de $S$. aucheniae. La MPO es una hemoproteína que se almacena principalmente en los gránulos azurófilos primarios de los neutrófilos PMNs representando el 5\% de la proteína total y es una de las proteínas más abundantes de estas células. También ha sido encontrada en los monocitos ( $1 \%$ de la proteína total) y en los macrófagos tisulares (Daugherty et al., 1994). Durante la activación y degranulación celular, la MPO es liberada tanto en vacuolas fagocíticas como directamente al espacio extracelular. Se reconoce que el nivel de actividad de la MPO está directamente relacionado con la concentración de neutrófilos en el tejido inflamado, por lo que la medición de esta actividad enzimática ha sido considerada un sensible marcador cuantitativo de la quimiotaxis e infiltración de neutrófilos en el proceso inflamatorio. También es considerada como un indicativo de estrés oxidativo (Moutaery, 2005; Cheng et al., 2006; Koksel et al., 2006).
En el presente trabajo se detecta la secreción de N-acetil-glucosaminidasa y que tiene como sustrato a la $\mathrm{N}$-acetil-glucosamina (NAG), la cual deriva de la glucosamina que, a su vez, es derivado de la glucosa. Se trata de una enzima lisosomal del tipo de las hidrolasas que se sintetiza en las células tubulares proximales renales y que por su alto peso molecular (entre 130-140 kDa) no se filtra por el glomérulo. Está implicada en la degradación de los mucopolisacáridos y glicoproteínas (Manjon, 2010). Las infecciones crónicas y las infecciones agudas repetidas estimulan la producción de anticuerpos en los individuos. También se produce una importante cantidad de anticuerpos en enfermedades no infecciosas, muchas de las cuales son de origen autoinmune. En ambos casos, la coexistencia de los antígenos y sus anticuerpos propicia la formación de complejos autoinmunes, tanto fijos en los sitios de lesión como solubles en la circulación. Los complejos inmunes usualmente son fijadores de complemento, de tal manera que su activación puede ocurrir tanto localmente como en la circulación. Los complejos inmunes solubles son altamente patogénicos debido a su propensión a depositarse en estructuras sujetas a alto tráfico o intercambio de sangre o plasma como las membranas basales de los endotelios vasculares, los glomérulos renales, los plexos coroideos y las articulaciones.

El efecto tóxico de los macroquistes sobre los leucocitos de conejos y su capacidad de inducir su degranulación puede ser uno de los mecanismos por el cual esta especie es altamente susceptible a la inoculación intramuscular de extracto de estos macroquistes, induciendo a una rápida muerte (Sam, et al., 1998). La muerte se explica como una intoxicación neurotóxica, pero los hallazgos de este trabajo también compromete un mecanismo anafiláctico por la alta toxicidad sobre los leucocitos sanguíneos y una rápida degranulación, quedando libres una gran cantidad de enzimas que colaboraría con el choque agudo que sufren los conejos y que los conduce a la muerte. 


\section{Conclusiones}

- El extracto de macroquistes de Sarcocystis aucheniae a dosis de 0.5, $1,50,500$ y $1000 \mathrm{ng} / 100 \mu \mathrm{l}$ y a 1 y 12 horas de incubación es altamente citotóxico para los leucocitos de conejo, provocando su degranulación, la cual fue evidenciada por la detección y cuantificación relativa de las enzimas leucocitarias mieloperoxidasa y $\mathrm{N}$-acetilglucosaminida.

- El extracto de macroquistes de $S$. aucheniae a concentraciones mayores de $5 \mathrm{ng} / 100 \mu \mathrm{l}$ es tóxico para los leucocitos circulantes de conejo.

\section{Literatura Citada}

1. Cheng H, Xia B, Zhang L, Zhou F, Zhang YX, Ye M, Hu ZW, et al. 2006. Matrine improves 2, 4, 6-trinitrobenzene sulfonic acid-induced colitis in mice. Pharmacol Res 53: 202-208.

2. Chileno M, Chávez A, Casas E, Chavera A, Puray N. 2011. Efectos tóxicos del contenido de dos tamaños de quistes de Sarcocystis aucheniae en conejos inoculados experimentalmente. Rev Inv Vet Perú 22: 360-368. doi: 10.15381/rivep.v22i4.336

3. Daugherty A, Dunn JL, Rateri DL, Heinecke JW. 1994. Myeloperoxidase, a catalyst for lipoprotein oxidation, is expressed in human atherosclerotic lesions. J Clin Invest 94: 437-444. doi: 10.1172/JCI117342

4. Giusti M, Lacchini R, Farina $\mathrm{OH}$, Rule R. 2012. Parámetros bioquímicos, hematológicos y productividad de conejos alimentados con dietas normo e hipoproteica. Acta Bioquim Clín Latinoam 46: 213-219.

5. Guerrero C, Hernández J, Alva J. 1967. Sarcocystis en alpacas. Rev Fac Med Vet UNMSM 21: 69-73.
6. Hiepe $F$, Hiepe $T$, Hlinak $R$, Jungmann R, Horsch R, Weidaner $B$. 1979. Experimentelle Infection des Menschen und Von Tieraffen (Ureopithecus allitrichus) mit SarKosporidienZysten Von Rind und schwein. Arch Exp Veterinaermed 33: 819-830.

7. Hiepe F, Lietzke L, Scheibner G, Jungmann R, Hiepe T, Montag T. 1981. Untersuchungen zur toxischen wirkung von extrakten aus Sarcocystis ovifelis - Macrozysten auf kanichen. Mli Vet Med 36: 908-910.

8. Hinostroza S, Manchego A, Sandoval N, Chiok Kim-Lam, More J. 2015. Expresión de citoquinas pro-inflamatorias de leucocitos de alpaca (Vicugna pacos) inducidos por el extracto de macroquistes de Sarcocystis aucheniae. Rev Inv Vet Perú 26: 328-341. doi: 10.15381/ rivep.v26i2.11007

9. Koksel O, Ozdulger A, Tamer L, Cinel $L$, Ercil M, Degirmenci U, Unlu S, Kanik A. 2006. Effects of caffeic acid phenethyl ester on lipopolysaccharideinduced lung injury in rats. Pulm Pharmacol Ther 19:90-95. doi: 10.1016/ j.pupt.2005.03.006

10. Lacy P. 2006. Mechanisms of degranulation in neutrophils. Allergy Asthma Clin Immunol 2: 98-108. doi: 10.1186/1710-1492-2-3-98

11. Leguía G. 1991. The epidemiology and economic impact of llama parasites. Parasitol Today 7: 54-56. doi: 10.1016/ 0169-4758(91)90190-Y

12. Leguía G Clavo N. 1989. Sarcocistiosis o «triquina». Bol Téc IVITA N. ${ }^{\circ} 7.19 \mathrm{p}$.

13. Manjon M. 2010. Estudio de $\mathrm{N}$-acetil beta-2 glucosaminidasa y otros marcadores de daño renal en la nefroangio-esclerosis hipertensiva. Tesis Doctoral. Granada, España: Univ de Granada. 256 p.

14. Moutaery AA. 2005. Proglumide attenuates experimental colitis in rats. Exp Toxicol Pathol 56: 327-332. doi: 10.1016/j.etp.2004.04.007 
15. Rodríguez M, Vergel N, Ospina LF, Calle J, Pinzón R. 2004. Evaluación de actividades enzimáticas elastasa y mieloperoxidasa como marcadores de desgranulación leucocitaria en modelos de inflamación aguda. Rev Col Cienc Quím Farm 34: 35-45.

16. Sam R, Mansilla I, Morales $C$, Ramírez A. 1998. Efecto tóxico de macroquistes de Sarcocystis aucheniae en ratones, cobayos y conejos. Rev Inv Pec IVITA 9(2): 11-18.

17. Senaud J, Cerna Z. 1978. Le cycle de developpement asexxue de Sarcocystis dispersa chez la somi eatude an microscope electronique. Protistologica 14: 155.

18. Tizard I. 2009. Inmunología veterinaria. $8^{\mathrm{a}}$ ed. México: Mc Graw-Hill. 592 p.

19. Urquhart GM, Armour J, Duncan JL, Dunn AM, Jennings FW. 1996. Veterinary parasitology. $2^{a}$ ed. Oxford, UK: Blackwell Science. 307 p.

20. Urquhart GM, Armour J, Duncan JL, Dun AM, Jennings FW. 2001. Parasitología veterinaria. $2^{\mathrm{a}}$ ed. Zaragoza: Acribia. 355 p. 